\title{
Carey-Fineman-Ziter syndrome with mutations in the myomaker gene and muscle fiber hypertrophy
}

Carola Hedberg-Oldfors, PhD, Christopher Lindberg, MD, PhD, and Anders Oldfors, MD, PhD

Neurol Genet 2018;4:e254. doi:10.1212/NXG.0000000000000254

\author{
Correspondence \\ Dr. Hedberg-Oldfors \\ carola.oldfors@gu.se
}

\begin{abstract}
\section{Objective}

To describe the long-term clinical follow-up in 3 siblings with Carey-Fineman-Ziter syndrome (CFZS), a form of congenital myopathy with a novel mutation in the myomaker gene $(M Y M K)$.
\end{abstract}

\section{Methods}

We performed clinical investigations, repeat muscle biopsy in 2 of the siblings at ages ranging from 11 months to 18 years, and whole-genome sequencing.

\section{Results}

All the siblings had a marked and characteristic facial weakness and variable dysmorphic features affecting the face, hands, and feet, and short stature. They had experienced muscle hypotonia and generalized muscle weakness since early childhood. The muscle biopsies revealed, as the only major abnormality at all ages, a marked hypertrophy of both type 1 and type 2 fibers with more than twice the diameter of that in age-matched controls. Genetic analysis revealed biallelic mutations in the MYMK gene, a novel c.235T>C; p.(Trp79Arg), and the previously described c.271C>A; p.(Pro91Thr).

\section{Conclusions}

Our study expands the genetic and clinical spectrum of MYMK mutations and CFZS. The marked muscle fiber hypertrophy identified from early childhood, despite apparently normal muscle bulk, indicates that defective fusion of myoblasts during embryonic muscle development results in a reduced number of muscle fibers with compensatory hypertrophy and muscle weakness. 


\section{Glossary}

CFZS = Carey-Fineman-Ziter syndrome; MYMK = myomaker.

Carey-Fineman-Ziter syndrome (CFZS, MIM 254940) is an autosomal recessive inherited disorder. Clinically, patients are described as having nonprogressive congenital myopathy with marked facial weakness, together with other clinical attributes such as Moebius and Pierre Robin sequence, facial abnormalities, and growth delay. Recently, autosomal recessive mutations in the gene myomaker (MYMK/TMEM8C) were found to be associated with CFZS. ${ }^{1}$

MYMK is a plasma transmembrane protein and is necessary for the fusion of mononuclear myoblasts to multinucleate myocytes in the skeletal muscle. ${ }^{2-6}$ In this article, we describe a family with 3 siblings affected with CFZS due to biallelic mutations in MYMK.

\section{Methods}

\section{Patients}

This Swedish family had 3 affected children with healthy unrelated parents (figure 1L). A summary of results from the clinical investigations is given in table.

\section{Figure 1 Clinical features and pedigree}
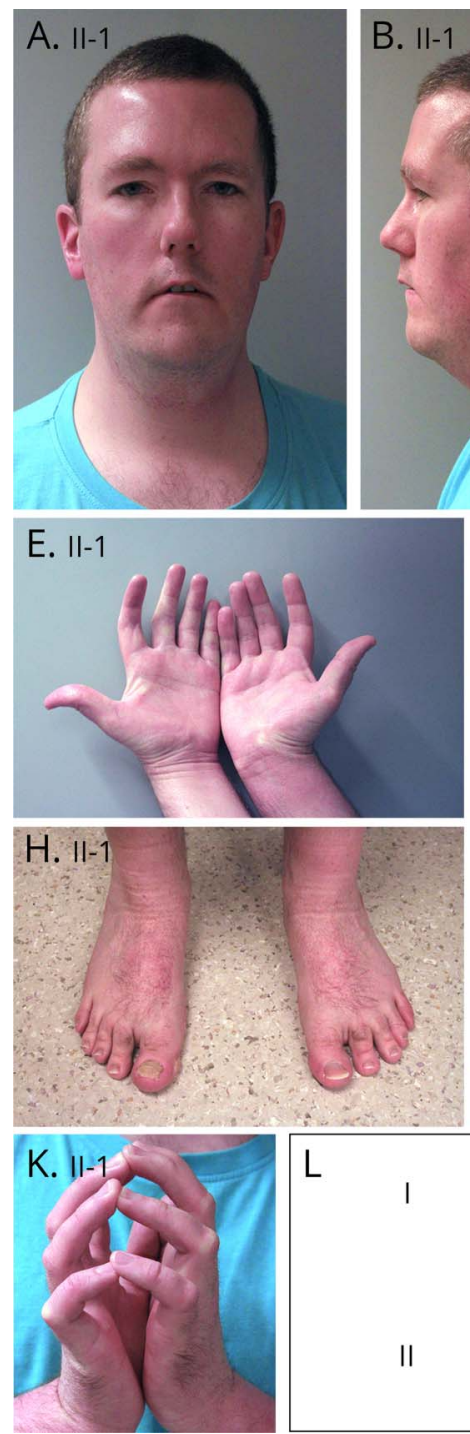
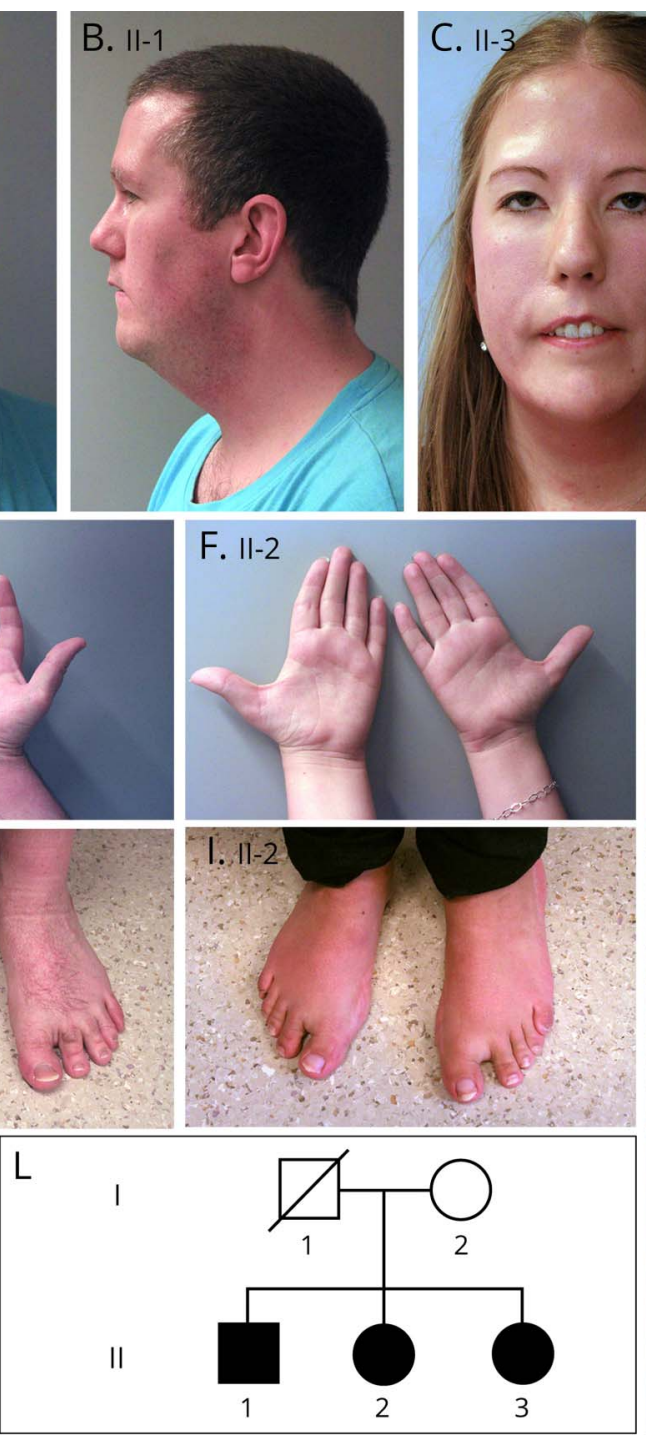
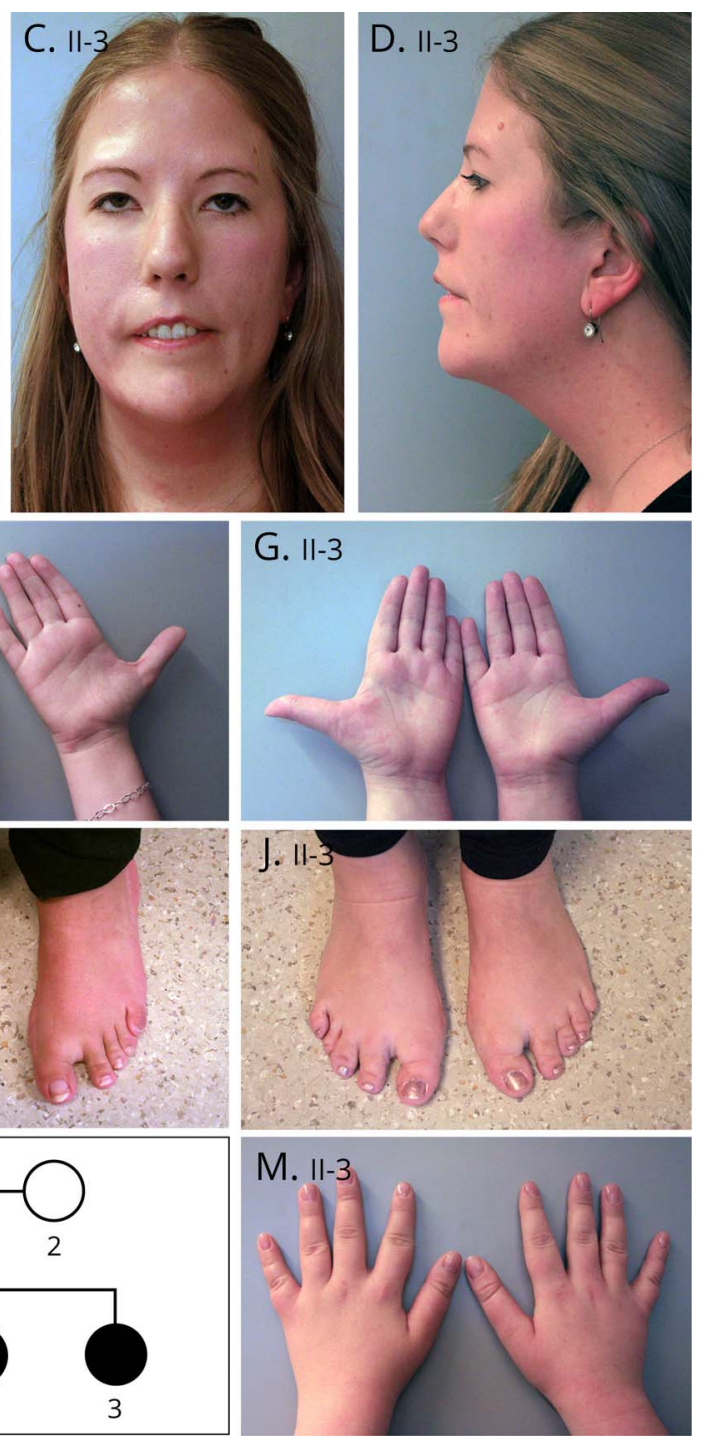

(A-D) Facial photographs of individuals II:1 and II:3 demonstrating facial weakness, slight ptosis, broad nasal tip, and in II:1, also slight retrognathia and some degree of epicanthus. (E-G and M) All 3 siblings had small hands with brachydactyly and short tapering fingers, with the thumbs situated proximally on the hands. (K) Individual II:1 also had camptodactyly. (H-J) They had small feet with short toes and sandal gap deformity. (I, J, and M) Individuals II:2 and II:3 appeared puffy on the dorsal aspects of the hands and feet. (L) Pedigree. 
Table Clinical findings

\begin{tabular}{|c|c|c|c|}
\hline Individual & II:1 & $11: 2$ & $11: 3$ \\
\hline Sex & Male & Female & Female \\
\hline Age at last examination (y) & 37 & 31 & 28 \\
\hline Descent & Swedish & Swedish & Swedish \\
\hline Height $(\mathrm{cm})^{\mathrm{a}}$ & 167 & 158 & 160 \\
\hline \multicolumn{4}{|l|}{ Phenotype } \\
\hline Facial weakness & Severe & Severe & Severe \\
\hline Broad nasal tip & Yes & Yes & Yes \\
\hline Retrognathia & Slight & Marked & Absent \\
\hline Dysarthria & Moderate & Severe & Moderate \\
\hline Tongue/hypoglossia & Small and short & Weakness & Weakness (slight) \\
\hline Palatal weakness & Yes & Yes & Yes (slightly) \\
\hline Pectoralis hypoplasia & Yes & No & No \\
\hline Scoliosis & No & Yes $\left(15^{\circ}-25^{\circ}\right)$ & No \\
\hline \multicolumn{4}{|l|}{ Muscle weakness } \\
\hline Neck flexors & None & Severe & Severe \\
\hline Hands & Moderate & Severe & None \\
\hline Proximal upper extremities & Slight & Slight & None \\
\hline Proximal lower extremities & Slight & Slight & Slight \\
\hline Distal lower extremities & Slight & Slight & Slight \\
\hline \multicolumn{4}{|l|}{ Laboratory testing } \\
\hline EMG & NA & Myopathic (age 17 y) & NA \\
\hline $\begin{array}{l}\text { Forced vital capacity } \\
\text { (L/\% predicted) }\end{array}$ & $2.15 / 49$ & $2.1 / 66^{\mathrm{b}}$ & $2.9 / 88$ \\
\hline Electrocardiography & Normal (age 36 y) & AV block grade II (age 30 y) & Normal (age 28 y) \\
\hline Echocardiography & Normal (age 36 y) & Normal (age 28 y) & Normal (age 20 y) \\
\hline Creatine kinase (IU/L) & $840(<294)$ & $1,200(<210)$ & $294(<210)$ \\
\hline Muscle pathology & Hypertrophy of type 1 and 2 fibers & Hypertrophy of type 1 and 2 fibers & NA \\
\hline DNA analysis $M Y M K$ & $\begin{array}{l}\text { Compound heterozygous; c. } 235 \mathrm{~T}>\mathrm{C} \text {; } \\
\text { c. } 271 \mathrm{C}>\mathrm{A}\end{array}$ & $\begin{array}{l}\text { Compound heterozygous; c.235T>C; } \\
\text { c. } 271 C>A\end{array}$ & $\begin{array}{l}\text { Compound heterozygous; c.235T >C; } \\
\text { c. } 271 \mathrm{C}>\mathrm{A}\end{array}$ \\
\hline Predicted protein change & p.(Trp79Arg); p.(Pro91Thr) & p.(Trp79Arg); p.(Pro91Thr) & p.(Trp79Arg); p.(Pro91Thr) \\
\hline
\end{tabular}

Abbreviations: MYMK = myomaker; NA, not available.

a Parental height: mother $163 \mathrm{~cm}$ and father $183 \mathrm{~cm}$.

b Technical difficulties.

All siblings presented at birth with hypotonia and feeding difficulties. They started to walk at around 15 months of age, but they used the Gower maneuver to come to an upright position. Individual II: 1 was operated for cryptorchidism at 6 weeks of age. All siblings had Achilles tendon contractures, but only individual II: 1 had been operated with lengthening of both Achilles tendons at the age of 9 years. They were hypermobile in most joints, including the elbows. All used glasses, individual II: 1 since 13 years of age due to hyperopia,
II: 2 since 6 years of age, and II. 3 since 26 years of age due to myopia. Individual II.2 had a hearing impairment involving low-frequency tones and started to use a hearing aid at 9 years of age. All had normal cognitive function.

At the time of genetic diagnosis in 2017, they all exhibited severe facial weakness together with dysmorphic features (figure $1 \mathrm{~A}-\mathrm{K}$ and $\mathrm{M}$, table). They showed slight bilateral ptosis, individual II:1 had slight limitation of eye abduction, and individuals II: 1 and II: 
2 had a slight defect in elevation of the eyes. Individual II:3 had a bifid uvula and an exostosis in the midline of the palate.

\section{Standard protocol approvals, registrations, and patient consents}

The study complied with the Declaration of Helsinki, and informed consent was obtained from the patients.

\section{Morphological analysis}

Open skeletal muscle biopsies from the vastus lateralis of the quadriceps muscle were performed. Specimens were snap-frozen in liquid propane chilled with liquid nitrogen for cryostat sectioning and histochemistry. ${ }^{7}$ Morphometric analyses of type 1 and type 2 muscle fibers were performed on adenosine triphosphatase-stained sections ( $\mathrm{pH}$ 9.4).

\section{Molecular genetic analysis}

Whole-genome sequencing was performed on genomic DNA from individual II:2 using the TruSeq PCR free library preparation kit, and the Illumina HiSeq $\mathrm{X}$ platform was used for sequencing (Illumina, San Diego, CA). The paired-end reads were aligned to the reference genome (hg19) using the CLC Biomedical Genomics workbench (Qiagen, Hilden, Germany). Data were analyzed using Ingenuity Variant Analysis (ingenuity.com/products/variant-analysis) (Qiagen). We performed a search for compound heterozygous or homozygous variants that were predicted to be damaging using SIFT (sorting intolerant from tolerant algorithm), Mutation Taster, and PolyPhen2, analyzing whether the variants affected conserved amino acids and whether they are uncommon in the population (using 1000 Genomes [1000genomes.org/], NHLBI Exome Sequencing Project [evs.gs.washington.edu/ EVS/], and the Genome Aggregation Database [gnomAD] [gnomad.broadinstitute.org/]), to reduce the number of variants. Sanger sequencing was used for confirmation and analysis of mutations identified in individuals I:2, II:1, and II:3.

\section{Results}

\section{Morphological analysis}

Muscle biopsy at the ages of 4.4 years and 6.3 years in individual II: 1 and at the ages of 11 months and 18 years in individual II: 2 showed (on all occasions) marked hypertrophy of both type 1 and type 2 fibers (figure 2, A-C). The median muscle fiber diameter was more than twice as large as in agematched controls (figure 2D). A few internalized nuclei were observed in individual II:2 at 18 years of age, and at that age, there were also some irregularities in the intermyofibrillar network as revealed by Nicotinamide adenine dinucleotide $(\mathrm{NADH})$-tetrazolium reductase staining (figure 2, B-C). There was no increase in interstitial connective tissue, and no necrotic or regenerating muscle fibers were observed.

Figure 2 Muscle histology and morphometric analysis demonstrating muscle fiber hypertrophy, occasional internalized nuclei and slight irregularity in the muscle fiber intermyofibrillar network

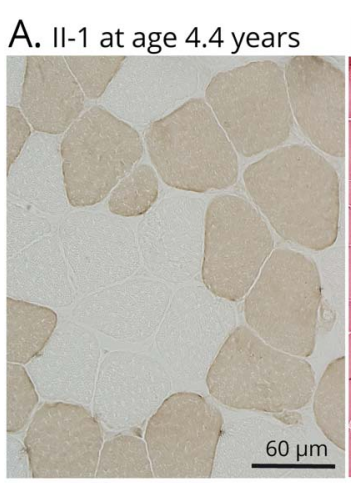

B. $11-2$ at age 18 years

C. II-2 at age 18 years

D

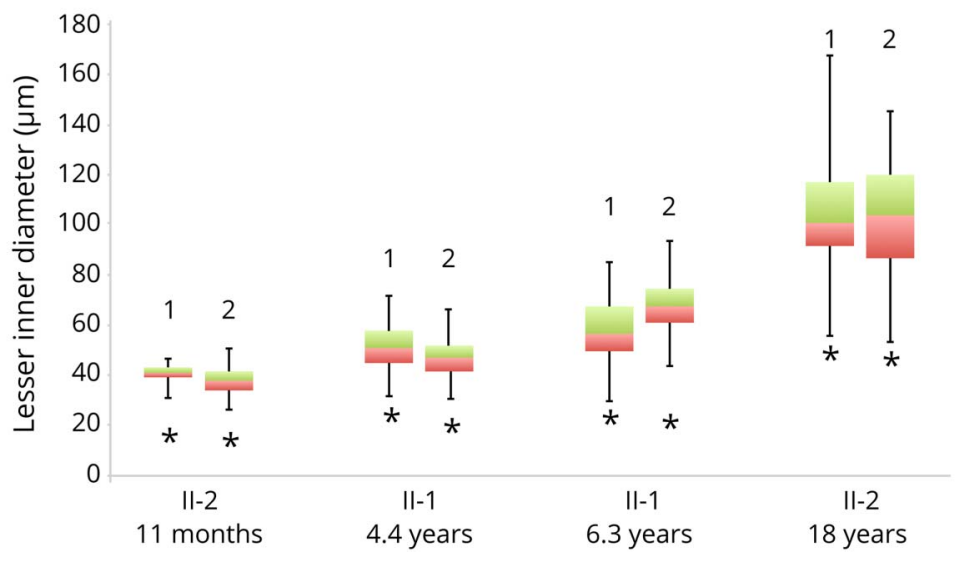

(A) Muscle fiber hypertrophy affecting both type 1 fibers (dark) and type 2 fibers (unstained) (adenosine triphosphatase, $\mathrm{pH}$ 4.3). (B) Muscle fiber hypertrophy and some internalized nuclei (hematoxylin and eosin). (C) Muscle fiber hypertrophy and patchy irregularities of the intermyofibrillar network (NADH-tetrazolium reductase). (D) Results from morphometric analysis. The lesser inner diameters (micrometers) of type 1 and type 2 fibers of 100 adjacent muscle fibers were measured in 4 different muscle biopsies from individuals II:1 and II:2 at different ages. Measurement of the lesser inner diameter avoids the risk of errors caused by oblique sections and was also used in the previously published measurements on controls that were used as references in this study. ${ }^{7}$ The results are given as medians, quartiles, and range. The median is at the border between the red and green boxes. The top of the green box is the 75th percentile of the sample, and the bottom of the red box is the 25th percentile. Normal mean diameters in age-matched controls are indicated with asterisks. Child controls included both males and females, and adult controls included females only. 1 = type 1 fibers; 2 = type 2 fibers. 


\section{Molecular genetic analysis}

Individuals II:1, II:2, and II:3 were all biallelic for 2 missense mutations in the MYMK gene (TMEM8C) (figure 3C). One was a missense mutation (c.235T $>\mathrm{C}$; p.(Trp79Arg)) not previously described. The second mutation was a previously described missense mutation
(c.271C>A; p.(Pro91Thr)) associated with CFZS (figure $3, \mathrm{~A}-\mathrm{D}){ }^{1}$

Other candidate genes associated with myopathies according to the NMD Gene Table 2017 (musclegenetable.fr/) were excluded. ${ }^{8}$ Sanger sequencing confirmed both mutations in all

Figure 3 Molecular genetics
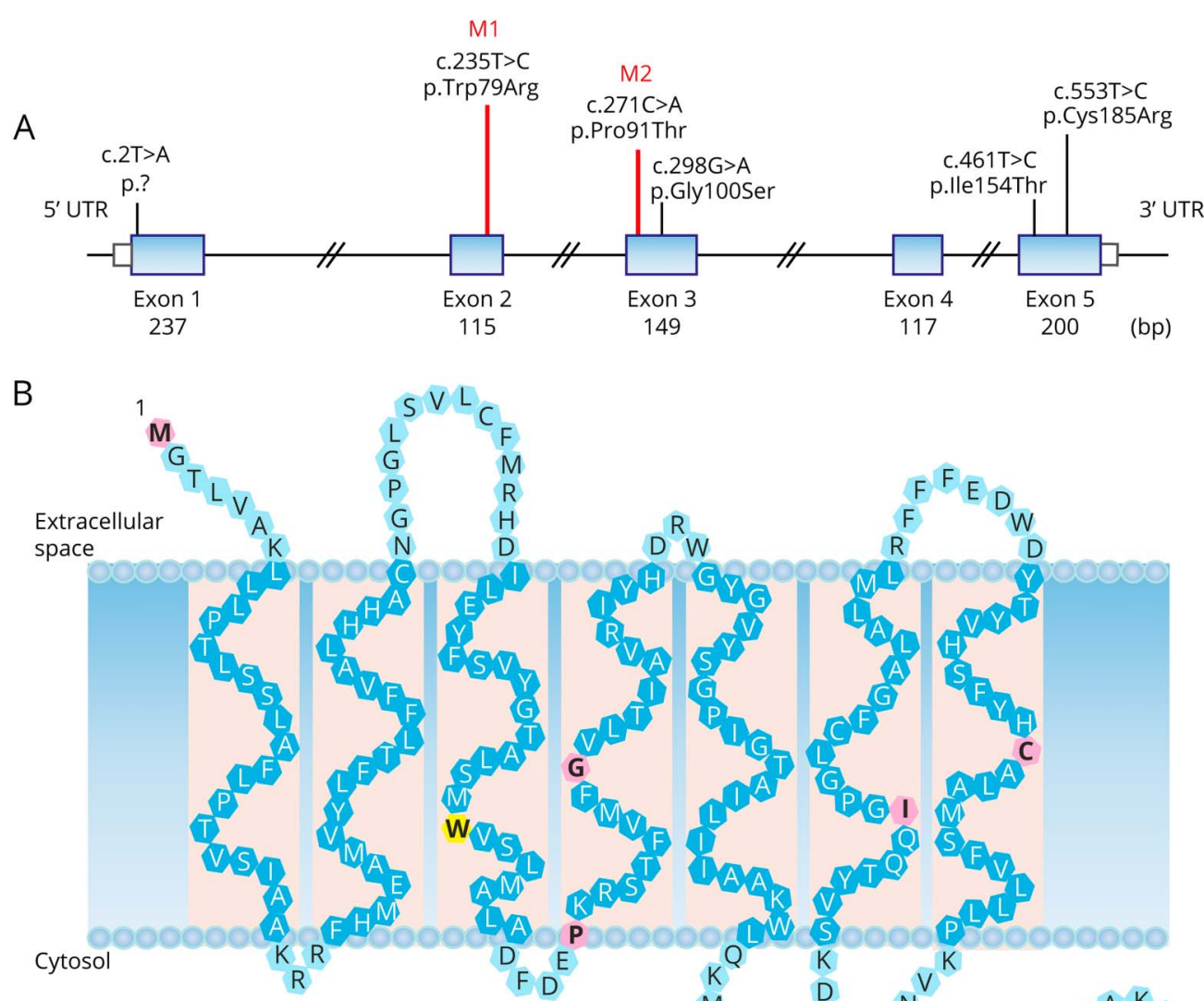

C

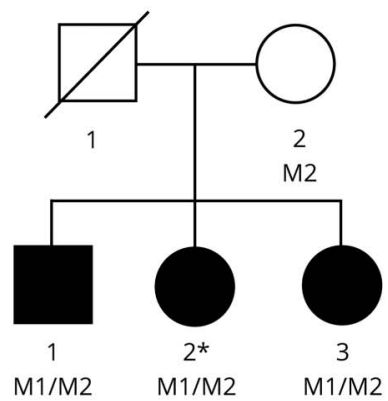

$\mathrm{D}$

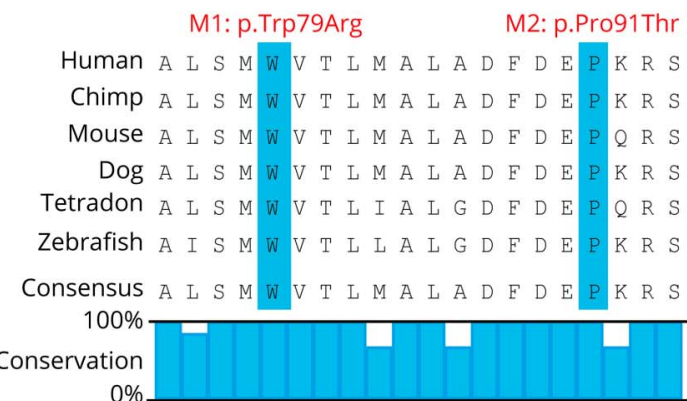

(A) Illustration showing all the pathogenic mutations identified in myomaker (MYMK). The novel mutation c.235T $>C$ (M1) and the previously described mutation c.271C $>$ A (M2) identified in the 3 siblings in this study are indicated (NM_001080483.2). (B) The 2D structure of MYMK showing the location of mutations (illustration adapted from reference 1). The p.Trp79Arg (M1) is located in one of the transmembrane domains and changes the large, nonpolar tryptophan (Trp/W) residue at position 79 to the large, positively charged arginine (Arg/R) residue-thus creating a shift in polarity from nonpolar to positively charged. (C) Pedigree of the family. Filled squares and circles indicate individuals with Carey-Finman-Ziter syndrome. Asterisk indicates the individual analyzed by whole-genome sequencing. (D) Illustration showing the evolutionary conservation of amino acids, the p.Trp79Arg (M1) with a conservation phyloP $p$ value of 5.834E-5. The blue bars in the upper part show the residues that were found to be mutated. 
3 siblings, and the mother was a heterozygous carrier of the mutation c.271C>A; p.(Pro91Thr).

\section{Discussion}

Here, we have described 3 siblings with CFZS due to biallelic missense mutations in MYMK, adding to the recent description of 8 individuals with MYMK mutations. ${ }^{1}$ Our cases show the same clinical spectrum of muscle weakness, where profound facial muscle weakness is the clinical hallmark of the disease. Severe neck flexor weakness, short stature, small hands and feet, and hyperlaxity of most joints in combination with distal contractures are additional clues to the correct diagnosis. Restrictive lung disease was described in the previous series of patients, and in 2 of our patients, a limitation in forced vital capacity was found, but to date, none of them have shown any clinical symptoms of hypoventilation. One of our patients had hearing impairment, which has also been described previously in CFZS. ${ }^{9}$

All siblings in this report were biallelic for $M Y M K$ missense mutations: p.(Pro91Thr) and p.(Trp79Arg). The p.(Pro91Thr) mutation has been identified in 4 of 5 apparently unrelated families already described. ${ }^{1}$ This mutation has also been identified in 328 of 276,516 alleles, but only in heterozygous individuals in the gnomAD database. The second mutation, p.(Trp79Arg), was not present in gnomAD, is predicted by in silico programs to be deleterious, and alters a phylogenetically highly conserved residue.

Our patients had had muscle hypotonia and weakness since early childhood and had been considered to have a congenital myopathy. The 4 muscle biopsies performed in 2 of the individuals at various ages, with the earliest biopsy performed at 11 months of age and the latest at 18 years, revealed a remarkable hypertrophy of both type 1 and type 2 muscle fibers as the only important pathology at all time points. Results from 1 muscle biopsy in a previous report demonstrated marked muscle fiber hypertrophy, but mainly affecting the type 2 fibers. ${ }^{1}$ This marked hypertrophy without any apparent increase in muscle bulk indicates a reduction in the number of muscle fibers to approximately one quarter of normal in our patients. One may postulate that muscle fiber hypertrophy, also seen in other neuromuscular diseases such as spinal muscular atrophy, ${ }^{10}$ compensates for the loss of functioning muscle fibers. At present, the markedly reduced number of muscle fibers seen in our CFZS patients from early childhood onward remains unexplained. However, as MYMK is essential for the fusion of mononuclear myoblasts to multinucleate myocytes during embryonic muscle development, ${ }^{4,11}$ one may speculate that a reduced MYMK function due to mutations in MYMK may play a role. Newborn $M Y M K^{-/-}$mice have profound muscle weakness, lack multinucleated muscle fibers, and die before postnatal day 7, suggesting that the lack of MYMK is incompatible with life. ${ }^{4}$ This suggests that the mutations identified in patients with CFZS in humans give rise to partially functioning MYMK protein, which has also been supported by functional studies. ${ }^{1}$ The p.(Pro91Thr) mutation has some residual function and is therefore compatible with life in combination with null alleles. ${ }^{1}$ The individuals described in this report carry the p.(Pro91Thr) mutation on 1 allele, and most likely, the combination with the mutation on the other allele, p.(Trp79Arg), leads to a severely reduced function of the MYMK protein.

Our study provides additional evidence for the association between CFZS and MYMK mutation. The marked muscle fiber hypertrophy despite the normal or reduced muscle bulk identified from early childhood indicates that defective fusion of myoblasts during embryonic muscle development results in reduced numbers of muscle fibers, with consequent hypertrophy and muscle weakness.

\section{Author contributions}

C. Hedberg-Oldfors performed the genetic analysis, interpreted the data, and drafted and revised the manuscript. C. Lindberg performed the clinical examinations, interpreted the data and revised the manuscript. A. Oldfors performed the muscle pathology analysis and drafted and revised the manuscript.

\section{Acknowledgment}

The authors thank Brith Leidvik for technical assistance and the patients for their support.

\section{Study funding}

This study was supported by the Research Fund for Neuromuscular Disorders in West Sweden and by the Swedish Research Council (project no. 2012-02014).

\section{Disclosure}

C. Hedberg-Oldfors reports no disclosures. C. Lindberg has received research support from the following foundations: Sweden Muskelfonden and Neuroförbundet. A. Oldfors serves on the editorial board of Neuromuscular Disorders; receives publishing royalties from Elsevier publishing for "Muscle Biopsy: A Practical Approach"; and has received research funding from the Swedish Research Council and the World Muscle Society. Full disclosure form information provided by the authors is available with the full text of this article at Neurology.org/NG.

Received January 20, 2018. Accepted in final form May 7, 2018.

\section{References}

1. Di Gioia SA, Connors S, Matsunami N, et al. A defect in myoblast fusion underlies Carey-Fineman-Ziter syndrome. Nat Commun 2017;8:16077.

2. Gamage DG, Leikina E, Quinn ME, Ratinov A, Chernomordik LV, Millay DP. Insights into the localization and function of myomaker during myoblast fusion. J Biol Chem 2017;292:17272-17289.

3. Goh Q, Millay DP. Requirement of myomaker-mediated stem cell fusion for skeletal muscle hypertrophy. Elife 2017;6:e20007.

4. Millay DP, O'Rourke JR, Sutherland LB, et al. Myomaker is a membrane activator of myoblast fusion and muscle formation. Nature 2013;499:301-305.

5. Millay DP, Sutherland LB, Bassel-Duby R, Olson EN. Myomaker is essential for muscle regeneration. Genes Dev 2014;28:1641-1646. 
6. Mitani Y, Vagnozzi RJ, Millay DP. In vivo myomaker-mediated heterologous fusion and nuclear reprogramming. FASEB J 2017;31:400-411.

7. Dubowitz V, Sewry CA, Oldfors A. Muscle Biopsy: A Practical Approach. Philadelphia, PA: Elsevier; 2013:1-592.

8. Kaplan JC, Hamroun D, Rivier F, Bonne G. The 2017 version of the gene table of neuromuscular disorders. Neuromuscul Disord 2016;26: 895-929.
9. Carey JC. The Carey-Fineman-Ziter syndrome: follow-up of the original siblings and comments on pathogenesis. Am J Med Genet A 2004;127A:294-297.

10. Kingma DW, Feeback DL, Marks WA, Bobele GB, Leech RW, Brumback RA. Selective type II muscle fiber hypertrophy in severe infantile spinal muscular atrophy. J Child Neurol 1991;6:329-334.

11. Chen EH, Olson EN. Unveiling the mechanisms of cell-cell fusion. Science 2005;308: 369-373. 


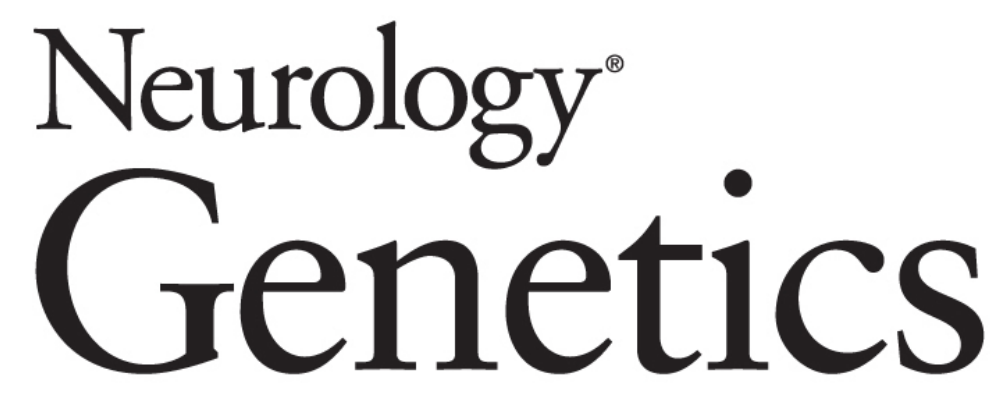

\section{Carey-Fineman-Ziter syndrome with mutations in the myomaker gene and muscle fiber hypertrophy \\ Carola Hedberg-Oldfors, Christopher Lindberg and Anders Oldfors Neurol Genet 2018;4; \\ DOI 10.1212/NXG.0000000000000254}

This information is current as of July 23, 2018

Updated Information \&
Services
References
Citations
Subspecialty Collections
Permissions \& Licensing
Reprints

\section{Updated Information \&}

References

\section{Citations}

\section{Subspecialty Collections}

Reprints including high resolution figures, can be found at: http://ng.neurology.org/content/4/4/e254.full.html

This article cites 10 articles, 3 of which you can access for free at: http://ng.neurology.org/content/4/4/e254.full.html\#\#ref-list-1

This article has been cited by 2 HighWire-hosted articles: http://ng.neurology.org/content/4/4/e254.full.html\#\#otherarticles

This article, along with others on similar topics, appears in the following collection(s):

\section{All Genetics}

http://ng.neurology.org//cgi/collection/all_genetics

Information about reproducing this article in parts (figures,tables) or in its entirety can be found online at:

http://ng.neurology.org/misc/about.xhtml\#permissions

Information about ordering reprints can be found online: http://ng.neurology.org/misc/addir.xhtml\#reprintsus

Neurol Genet is an official journal of the American Academy of Neurology. Published since April 2015, it is an open-access, online-only, continuous publication journal. Copyright Copyright @ 2018 The Author(s). Published by Wolters Kluwer Health, Inc. on behalf of the American Academy of Neurology.. All rights reserved. Online ISSN: 2376-7839.

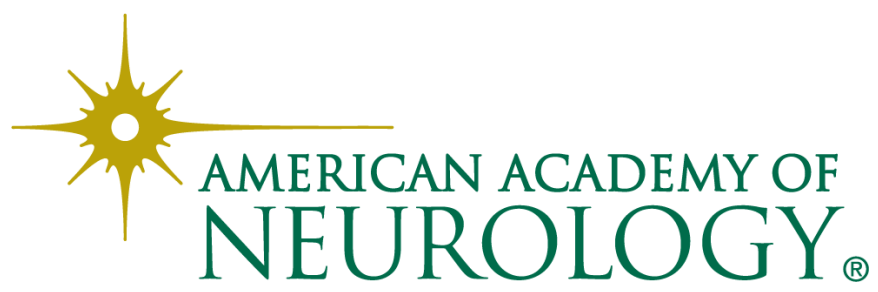

